\title{
Inking in a Blue-Ringed Octopus, Hapalochlaena lunulata, with a Vestigial Ink Sac ${ }^{1}$
}

\author{
Cbristine L. Huffard and R. L. Caldwell ${ }^{2}$
}

\begin{abstract}
Here we report for the first time that adult Hapalocblaena lunulata (Quoy \& Gaimard, 1832), which has a vestigial ink sac, is capable of inking. Ink was released under three different agonistic conditions: female-female aggression, rejection of mating attempt, and when attacked by a predator. We observed no apparent reaction to the ink by the other animals involved in these interactions.
\end{abstract}

INK SACS ARE FOUND in most shallow-water coleoid cephalopods (octopuses, squids, and cuttlefish), but the function of inking as a defensive behavior of cephalopods rarely has been investigated. Released ink is believed to (1) provide a smoke screen for escape; (2) serve as a pseudomorph; or possibly (3) block olfactory or taste receptors (Schäfer 1956, Moynihan and Rodaniche 1977, Hanlon and Messenger 1996, Boletzky 1997). Cephalopod ink elicits jetting in squids (Gilly and Lucero 1992) and increases ventilation rate in cuttlefish (Boal and Golden 1999). This may indicate its function as an alarm pheromone to warn conspecifics, but such behaviors also could be elicited if the ink was a general irritant. In fact, some predators may be attracted to ink (Grüninger 1997).

In octopuses, the reduction or loss of an ink sac may have evolved independently in at least three shallow-water taxa that have developed other effective defenses. Ameloctopus littoralis Norman, 1992, a small, intertidal octopus, lacks an ink sac but readily autotomizes its long arms (Norman 1992). The undescribed "Wonderpus," another longarmed, shallow-water octopus capable of arm autotomy, has a severely reduced ink sac

1 Manuscript accepted 31 October 2001.

${ }^{2}$ Department of Integrative Biology, University of California at Berkeley, Berkeley, California 947203140 (phone: 510-642-1391; fax: 510-643-6264; E-mail: 4roy@socrates.berkeley.edu).

Pacific Science (2002), vol. 56, no. 3:255-257 (C) 2002 by University of Hawai'i Press All rights reserved
(M. D. Norman and F. G. Hochberg, pers. comm.) and does not ink despite considerable disturbance (C.L.H., pers. obs.). Blue-ringed octopuses, Hapalocblaena spp., are known best for their potent, tetrodotoxin-laden venom (Norman 2000). The genus is diagnosed by the presence of multiple iridescent blue rings or lines on the body and arms and marked reduction of the ink sac in adults (Robson 1929). Although Robson did not speculate on the vestigial ink sac in adults, he did note its drastic reduction in size in the type species, H. lunulata (Quoy \& Gaimard, 1832), compared with Hapalochlaena maculosa (Hoyle, 1883).

Hatchling Hapalocblaena are able to expel ink: H. fasciata (Hoyle, 1886) (Tranter and Augustine 1973 [taxonomy according to Stranks and Lu 1991]); H. maculosa (Stranks and Lu 1991); H. lunulata (R.L.C., pers. obs.). However, $H$. fasciata does not ink after they are 4 weeks old (Tranter and Augustine 1973). Juvenile (5- to 6-mm mantle length) H. maculosa expel ink, but the reservoir degenerates with age (Stranks and Lu 1991) until neither production nor release of ink occurs in adult $H$. maculosa (Roper and Hochberg 1988, Stranks and Lu 1991). Tranter and Augustine (1973) also reported that $H$. fasciata does not eject ink as adults. Recently, two undescribed species of Hapalocblaena were noted to ink as adults (sp. 3 and sp. 5 of Norman 2000). We therefore can no longer assume that degeneracy of the reservoir in Hapalocblaena spp. obligates the loss of the ability to ink.

During laboratory studies on $H$. lunulata obtained from Indonesia, we recorded seven 


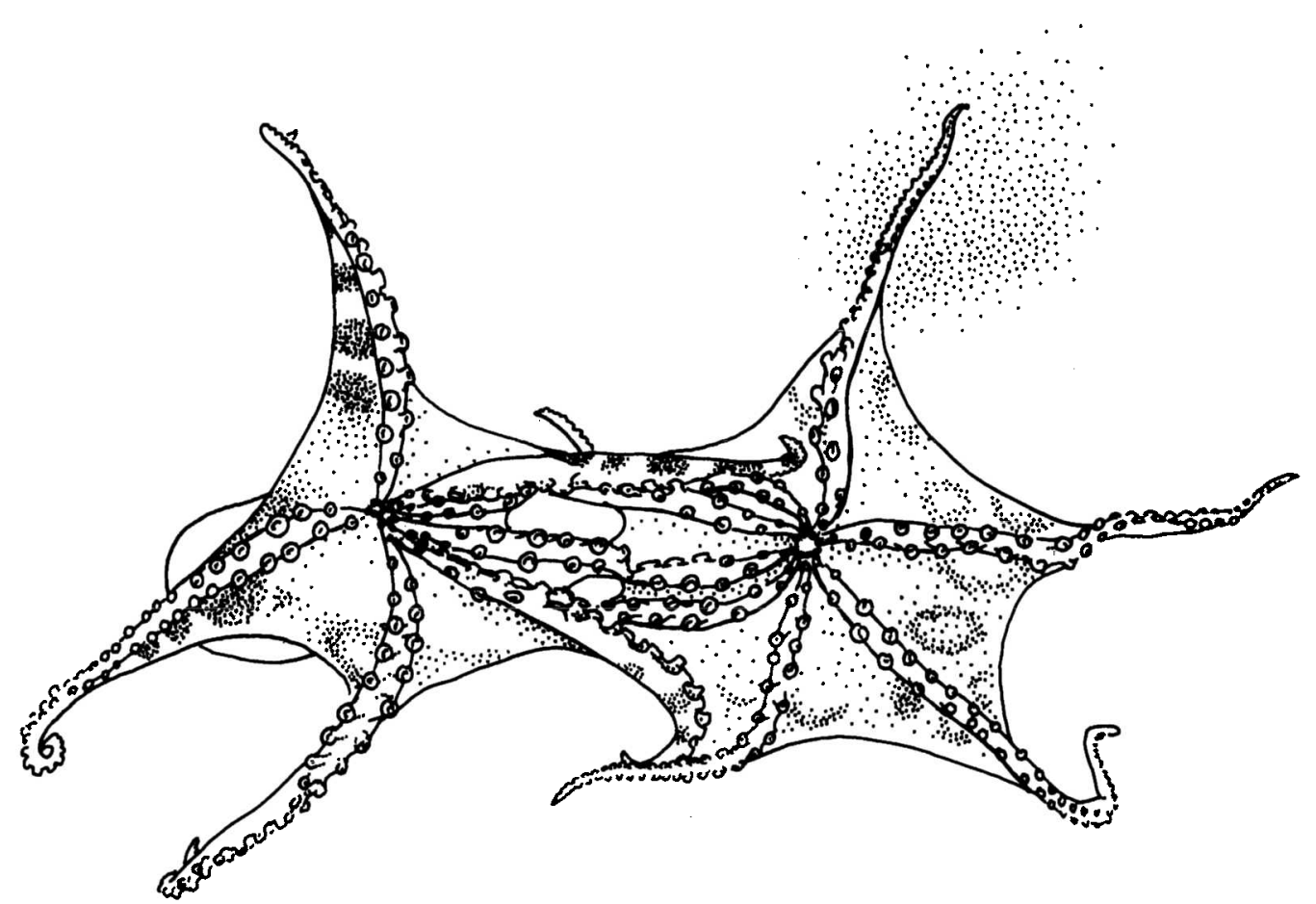

FIgURE 1. Line drawing taken from a frame of video of two female Hapalocblaena lunulata interlocking arms while engaged in an aggressive interaction. The animal on the right released the diffuse cloud of ink (top, right).

instances when adults released a single, poorly defined cloud of brown ink. In each case, the small puff of ink diffused in seconds. The octopuses ejecting the ink did not jet from the inked area. We observed no apparent direct reaction to the ink by the other animals involved in these situations.

Two adult octopuses (one male and one female) inked as they attempted to escape from an attack by a stomatopod, Odontodactylus scyllarus (Linnaeus, 1758). Another male inked as it jetted away from a nearby stomatopod. A female inked as she rejected the approach of a male with which she had previously mated, and a brooding female inked while a male mounted her, attempting to mate. An adult male inked near the end of a mating session initiated by the female (Cambridge Studios 1998). Finally, a female inked near the end of a long series of approaches and aggressive interactions with another fe- male (Figure 1). The two females had wrestled intensely, released, reapproached with arms and web spread, and touched distal portions of the arms. The smaller female inked and eventually retreated from the advances of her opponent.

The inkings we observed by $H$. lunulata are not easily attributable to any of the usual explanations of inking behavior mentioned previously. Because the thin, transient cloud of ink released neither impairs visibility nor retains any shape in the water column, it does not serve as a smoke screen or a pseudomorph. Cephalopod ink may irritate the chemosensory systems of some animals (Gilly and Lucero 1992), but it appears to offer no protection from $O$. scyllarus. Attacking stomatopods continued to pursue, and eventually killed, the two octopuses that had inked. Because the highly visual $O$. scyllarus may be an effective predator even with dulled olfac- 
tory receptors, the ability of $H$. lunulata ink to inhibit the approach of predators that rely more on chemosensory information should be investigated. In five of the seven situations, ink was released after provocation by a conspecific. No animal jetted immediately from the area, as would occur in response to an alarm.

We suggest that ink is released by $H$. $l u$ nulata not as an adaptive defense, but rather as an artifact of unusually strong mantle contraction. Hatchlings ink primarily during forceful jet swimming (R.L.C., pers. obs.). Reexamination of videotaped inking behavior by adults showed that release of ink corresponded with very strong mantle contractions. Future studies may help elucidate whether the ink (1) subdues chemosenses; (2) is an artifact of unusually powerful mantle contractions; or (3) serves a novel use in $\mathrm{Ha}$ palochlaena spp.

\section{Literature Cited}

Boal, J. G., and D. K. Golden. 1999. Distance chemoreception in the common cuttlefish Sepia officianalis (Mollusca, Cephalopoda). J. Exp. Mar. Biol. Ecol. 235:307-317.

Boletzky, S. V. 1997. Puffing smoke-rings under water: The functional morphology of cephalopod ink injectors. Vie Milieu 47:180-181.

Cambridge Studios. 1998. The mysteries of the sea. Videotape.

Gilly, W. F., and M. T. Lucero. 1992. Behavioral responses to chemical stimulation of the olfactory organ in the squid Loligo opalescens. J. Exp. Biol. 162:209-229.

Grüninger, T. 1997. The predator-prey relationship between the California moray eel (Gymnotborax mordax) and the two-spotted octopus (Octopus bimaculoides). M.S. thesis,
University of San Diego, San Diego, California.

Hanlon, R. T., and J. B. Messenger. 1996. Cephalopod behaviour. Cambridge University Press, Cambridge.

Moynihan, M. H., and A. F. Rodaniche. 1977. Communication, crypsis and mimicry among cephalopods. Pages 293-302 in T. A. Sebeok, ed. How animals communicate. Indiana University Press, Bloomington.

Norman, M. D. 1992. Ameloctopus litoralis, gen. et. sp. nov. (Cephalopoda: Octopodidae), a new shallow water octopus from Australian waters. Invertebr. Taxon. 6:567-582.

2000. Cephalopods: A world guide. ConchBooks, Hackenheim.

Robson, G. C. 1929. A monograph of the Recent Cephalopoda. I. Octopodinae. British Museum (Natural History), London.

Roper, C. F. E., and F. G. Hochberg. 1988. Behavior and systematics of cephalopods from Lizard Island, Australia, based on color and body patterns. Malacologia 29:153-193.

Schäfer, W. 1956. Die Schutzwirkung der Tintenfisch-Tinte. Nat. Volk (Frankf.) 86:24-26.

Stranks, T. N., and C. C. Lu. 1991. Postembryonic development of the blue-ringed octopus Hapalocblaena maculosa. Pages 713-722 in Proceedings of the Third International Marine Biological Workshop: The marine flora and fauna of Albany, West Australia, Vol. 2. Western Australian Museum, Perth.

Tranter, D. J., and O. Augustine. 1973. Observations on the life history of the blueringed octopus Hapalocblaena maculosa. Mar. Biol. (Berl.) 18:115-128. 